\title{
Análise epidemiológica das arboviroses emergentes e reemergentes no Brasil entre os
} anos de 2019 e 2020

\author{
Epidemiological analysis of emerging and re-emerging arbovirus infections in Brazil between the
} years 2019 and 2020

Análisis epidemiológico de las infecciones por arbovirus emergentes y reemergentes en Brasil entre

los años 2019 y 2020

\begin{abstract}
Resumo
Objetivou-se analisar a incidência e a prevalência das arboviroses (dengue, chikungunya e zika) transmitidas pelo Aedes aegypti entre os anos de 2019 a 2020, bem como os fatores que promovem a sua propagação. Dessa forma, realizou-se uma revisão bibliográfica de natureza qualitativa e de caráter descritivo e exploratório. Sendo utilizada a questão norteadora: Qual a situação epidemiológica das arboviroses no Brasil entre os anos de 2019 a 2020? A busca foi realizada nos bancos de dados: PubMed e SciELO, assim como, foram utilizados dados epidemiológicos pertencentes ao site do Ministério da Saúde/Brasil. Os critérios de inclusão foram: artigos nacionais e internacionais completos, disponibilizados de forma gratuita, publicados entre janeiro de 2008 a janeiro de 2021 em inglês e português. No que diz respeito a saúde pública, os arbovírus têm gerado uma grande preocupação no mundo. Em 2020, foram notificados 971.136 casos prováveis de dengue até a Semana Epidemiológica (SE) 46, com taxa de incidência de 462,1 casos/100 mil habitantes, para Chikungunya, entre as SE 1 e 46, obteve-se 78.808 casos prováveis notificados, com taxa de incidência de 37,5 casos/100 mil habitantes. E para Zika, entre as SE 1 a 43, tiveram 7.006 casos prováveis notificados no Brasil, com taxa de incidência de 3,3 casos/100 mil habitantes. Portanto, fica claro que as arboviroses ocasionam um grande impacto na saúde pública que vão desde a identificação do agente causador até as medidas de controle dos vetores. Com isso, é ressaltado a importância de saneamento como método de controle da incidência e prevalência das infecções por arbovírus.
\end{abstract}

Palavras-chave: Arbovírus; Brasil; Epidemiologia; Infecções por arbovírus; Insetos.

\begin{abstract}
The objective was to analyze the incidence and prevalence of arbovirus infections (dengue, chikungunya and zika) transmitted by Aedes aegypti between the years 2019 to 2020, as well as the factors that promote their propagation. Thus, a bibliographic review of a qualitative nature and of a descriptive and exploratory character was carried out. The guiding question was: What is the epidemiological situation of arbovirus infections in Brazil between the years 2019 and 2020? The search was conducted in the databases: PubMed and SciELO, as well as, epidemiological data belonging to the Ministry of Health/Brazil website was used. The inclusion criteria were: complete national and international articles, available free of charge, published between January 2008 and January 2021 in English and Portuguese. As far as public health is concerned, arboviruses have generated great concern in the world. In 2020, 971.136 probable cases of dengue were reported up to Epidemiological Week (EW) 46, with an incidence rate of 462,1 cases/100.000 inhabitants, for Chikungunya, between EW 1 and 46, 78.808 probable cases were reported, with an incidence rate of 37,5 cases/100.000 inhabitants. In addition, for Zika, between EW 1 and 43, there were 7.006 probable cases reported in Brazil, with an incidence rate of 3,3 cases/100.000 inhabitants. Therefore, it is clear that arbovirus infections cause a huge impact on public health that goes from the identification of the causative agent to the vector control measures. With this, the importance of sanitation as a method to control the incidence and prevalence of arbovirus infections is emphasized.
\end{abstract}

Keywords: Arbovirus Infections; Arboviruses; Brazil; Epidemiology; Insecta.

\section{Resumen}

El objetivo fue analizar la incidencia y prevalencia de las infecciones por arbovirus (dengue, chikungunya y zika) transmitidas por Aedes aegypti entre los años 2019 a 2020, así como los factores que promueven su propagación. Así, se realizó una revisión bibliográfica de naturaleza cualitativa y de carácter descriptivo y exploratorio. La pregunta 
guía fue: ¿Cuál es la situación epidemiológica de las infecciones por arbovirus en Brasil entre los años 2019 a 2020 ? La búsqueda se realizó en las bases de datos PubMed y SciELO, así como, se utilizaron datos epidemiológicos pertenecientes al sitio web del Ministerio de Salud/Brasil. Los criterios de inclusión fueron: artículos completos nacionales e internacionales, disponibles de forma gratuita, publicados entre enero de 2008 y enero de 2021 en inglés y portugués. En lo que respecta a la salud pública, los arbovirus han generado una gran preocupación en el mundo. En 2020, se notificaron 971.136 casos probables de dengue hasta la Semana Epidemiológica (SE) 46, con una tasa de incidencia de 462,1 casos/100.000 habitantes, para el Chikungunya, entre las SE 1 y 46, se notificaron 78.808 casos probables, con una tasa de incidencia de 37,5 casos/100.000 habitantes. Y para el Zika, entre el SE 1 y el 43, se notificaron 7.006 casos probables en Brasil, con una tasa de incidencia de 3,3 casos/100.000 habitantes. Por lo tanto, está claro que las infecciones por arbovirus causan un gran impacto en la salud pública que va desde la identificación del agente causante hasta las medidas de control del vector. Con esto, se destaca la importancia del saneamiento como método de control de la incidencia y prevalencia de las infecciones por arbovirus.

Palabras clave: Arbovirus; Brasil; Epidemiología; Infecciones por arbovirus; Insectos.

\section{Introdução}

As doenças infecciosas demonstram algumas características que as distinguem de outras doenças humanas, como o traço explosivo e imprevisível em escala global, a propagação, estreita relação com o comportamento humano e o meio ambiente e a capacidade de erradicação e/ou prevenção (Fauci \& Morens, 2012).

Muitos dos microrganismos que causam doenças infecciosas humanas possuem uma origem zoonótica, isto é, existem naturalmente em um ciclo envolvendo vetor e animais selvagens, como por exemplo, macacos ou aves. No entanto, devido às atividades humanas relacionadas principalmente às atividades econômicas, muitos insetos vetores, como os mosquitos, tornaram-se sinantrópicos, o que favorece a disseminação de patógenos para os humanos. Portanto, nos últimos quinze anos, foi visto o surgimento de algumas doenças transmitidas por mosquitos, em especial arbovírus, como zika, Chikungunya e o Nilo Ocidental, em países distintos das Américas (Lima-Camara, 2016).

Paz e Bercini (2009), definem doença emergente como, a aparição ou a identificação de um problema de saúde novo, ou também como novo agente infeccioso, exemplificando, tem-se a AIDS, a febre hemorrágica pelo vírus Ebola, a encefalite espongiforme (doença da vaca louca) e a hepatite C, dentre outras. Já doenças reemergentes, apontam alteração no desempenho epidemiológico de doenças já identificadas, que possuíam controle, porém voltaram a indicar mudança no comportamento epidemiológico de doenças já conhecidas, que haviam sido controladas, mas que voltaram a demonstrar ameaça à saúde do homem. Como por exemplo, a cólera, dengue e a expansão da leishmaniose visceral.

Os arbovírus são vírus disseminados por artrópodes, e são assim nomeados não apenas porque são transmitidos por artrópodes, mas especialmente porque parte de seu ciclo de replicação ocorrem em insetos. Através da picada de artrópodes hematófagos, tem-se a propagação de doenças aos humanos e aos outros animais. E os arbovírus que infectam os animais de sangue quente e humanos são pertencentes as famílias: Rhabdoviridae, Reoviridae, Togaviridae, Bunyaviridae e Flaviviridae (Rust, 2012). Cleton, et al., (2012), ressalta que muitos dos arbovírus existentes são zoonóticos, e estima-se que se tenha mais de 545 espécies de arbovírus, e dentre essas 150 estão associadas a doenças em humanos.

Dengue, Chikungunya e Zika são arboviroses que têm causado muito sofrimento e dor nas pessoas e impactando na sobrecarga dos sistemas de saúde. Os surtos recentes exibiram a vulnerabilidade nos controles destas infecções e nas suas ações de prevenção. Contudo, ampliou-se a complexidade das infecções por arbovírus (Queiroz, et al., 2020). Dessa forma, objetivou-se analisar a incidência e a prevalência das arboviroses (dengue, chikungunya e zika) transmitidas pelo Aedes aegypti entre os anos de 2019 a 2020, bem como os fatores que promovem a sua propagação.

\section{Metodologia}

Este trabalho apresenta uma revisão bibliográfica de natureza qualitativa, no qual os procedimentos se caracterizam a métodos de interpretação dos fenômenos pelo autor, sem procurar expor ou calcular eventos, e, normalmente, não se utiliza 
instrumentos estatísticos para avaliação das informações (Pereira, et al., 2018). Como também, a pesquisa possui caráter descritivo que tem o intuito de assimilar o fenômeno estudado e suas particularidades, com a pretensão de especificar com exatidão os eventos e fenômenos de um fato estabelecido (Triviños, 1987; Godoy, 1995). E também exploratório, uma vez que se tem o intuito de amplificar a compreensão sobre um determinado fenômeno (Gil, 2002).

Para isso utilizou-se a questão norteadora: Qual a situação epidemiológica das arboviroses no Brasil entre os anos de 2019 a 2020? Sendo a busca realizada nos bancos de dados: PubMed e SciELO, utilizando os descritores: "Arboviruses", "Arbovirus Infections", "Insecta" e "Epidemiology" cadastrados no DeCS/MeSH e empregando o operador booleano AND. Assim como, foram utilizados dados epidemiológicos pertencentes ao site do Ministério da Saúde/Brasil. Os critérios de inclusão foram: artigos nacionais e internacionais completos, disponibilizados de forma gratuita, publicados entre janeiro de 2008 a janeiro de 2021 em inglês e português. Bem como os critérios de exclusão foram: artigos com acesso restrito e/ou duplicados, resumos, relatos de experiência e nos quais não abordavam os fatores de propagação das arboviroses. E para a organização dos dados, as informações coletadas foram implantadas no Excel® e Microsoft Word®.

\section{Resultados e Discussão}

No primeiro momento, foi pesquisado nas bases de dados PubMed e SciELO os descritores "Arboviruses", "Arbovirus Infections", "Insecta" e "Epidemiology". Na PubMed, obteve-se um retorno de 354 artigos, e na SciELO 89, totalizando 443, conforme Quadro 1.

Quadro 1 - Retorno dos descritores nas bases de dados PubMed e SciELO.

\begin{tabular}{|c|c|c|}
\hline Base de dados & PubMed & SciELO \\
\hline Descritores & $\begin{array}{c}\text { Arboviruses AND Arbovirus Infections } \\
\text { AND Insecta AND Epidemiology }\end{array}$ & $\begin{array}{c}\text { Arboviruses AND Arbovirus Infections } \\
\text { AND Insecta AND Epidemiology }\end{array}$ \\
\hline Retorno & 354 & 89 \\
\hline Total & \multicolumn{2}{|c|}{443} \\
\hline
\end{tabular}

Fonte: Autores (2020).

No segundo momento, foi feita uma leitura nos títulos e resumos dos artigos para validar os critérios de inclusão, sendo excluídos 339 artigos. E no terceiro momento, foi feita uma leitura detalhada para avaliar o conteúdo e se eles estão de acordo com o tema proposto, sendo incluídos 20 artigos e excluído 84.

Como também foram utilizados dois boletins epidemiológicos do Ministério da Saúde/Brasil, sendo um de 2019, referente as Semanas Epidemiológicas (SE) 1 a 52 (30/12/2018 a 30/12/2019) para dengue e chikungunya, e 1 a 48 (30/12/2018 a 16/12/2019) para Zika. E outro de 2020, referente as SE 1 a 46 (29/12/2019 a 14/11/2020) para dengue e chikungunya, e 1 a 43 (29/12/2019 a 24/10/2020) para Zika.

O Brasil é o quinto maior país do mundo possuindo uma extensão territorial de 8.514.876 quilômetros quadrados, só perdendo para a Rússia, Canadá, China e Estados Unidos (Instituto Brasileiro de Geografia e Estatística, 2020). Além disso, o país está localizado em uma área tropical que abarca várias zonas climáticas como o trópico úmido no Norte, o semiárido no Nordeste e áreas temperadas no Sul. Estima-se que mais de 20\% do total de espécies do planeta se encontre no Brasil, e dentro desta mega biodiversidade tem-se os invertebrados de interesse médico, veterinário e agronômico incluindo as espécies responsáveis pela transmissão das principais arboviroses do país (Ministério do Meio Ambiente, 2020).

No que diz respeito a saúde pública, os arbovírus têm gerado uma grande preocupação no mundo. Culicídeos 
disseminam os vírus mais importantes para a saúde do homem, principalmente dos gêneros Culex e Aedes, embora ainda existam arbovírus transmitidos por outros vetores, como carrapatos e flebotomíneos (Weaver \& Reisen, 2010).

A transmissibilidade viral exercida pelo vetor pode ser influenciada por uma junção de elementos que incluem fatores externos (urbanização, temperatura, mudança climática) e internos (imunidade, genética, expectativa de vida). A temperatura em particular, tem um papel importante, pois os insetos vetores são sensíveis às mudanças de temperatura (Samuel, et al., 2016).

Ainda Samuel, et al., (2016) enfatizam que, embora muitas variáveis possam afetar a capacidade dos vetores artrópodes de adquirirem e subsequentemente transmitirem patógenos, apenas os vírus que podem superar as barreiras de replicação e propagação em insetos, serão transmitidos. Após o repasto sanguíneo contendo partículas de vírus infecciosas, o intestino médio dos artrópodes poderá ser infectado. O vírus é amplificado no epitélio intestinal, podendo se espalhar para os tecidos periféricos do mosquito, que por ventura pode ser amplificado novamente antes de chegar às glândulas salivares. O sucesso da infecção e amplificação do vírus nas glândulas salivares é um pré-requisito para a transmissão ao hospedeiro vertebrado.

Poucos vírus perderam a exigência de amplificação enzoótica e criaram epidemias urbanas tendo o ser humano como amplificador vertebrado de forma exclusiva. O que é o caso dos vírus da Dengue (DENV), Chikungunya (CHIKV) e Zika (ZIKV) (Weaver \& Reisen, 2010).

O vírus da dengue (DENV) é representado por quatro sorotipos, sendo eles DENV-1 a DENV-4, e a sua propagação é realizada pelo mosquito Aedes aegypti. A ocorrência de mais de um sorotipo DENV-1 e DENV-2 foi por volta da década de 40, já o DENV-3 e DENV-4 foram isolados pela primeira vez durante a epidemia nas Filipinas em 1956 (Alen \& Schols, 2012). A primeira evidência de DENV ocorreu no final do século 18, com simultâneas epidemias em Jacarta, Indonésia, Cairo e Egito em 1779 e na Filadélfia e Pensilvânia, em 1780. A amplificação a nível global e a elevação da incidência da dengue sucederam-se com o crescimento das cidades e a globalização (Lopes, et al., 2014).

Os flavivírus mais importantes no Brasil são os DENV, habitando o país, provavelmente há muitos anos. A literatura demonstra um provável surto da doença que pode ter causado febre, dores musculares e nas articulações no estado do Rio de Janeiro em 1846. Outros surtos podem ter ocorrido nas regiões Nordeste, Sudeste e Sul do Brasil no século 19. O efeito da temperatura na transmissibilidade do DENV tem sido amplamente investigado, pois a temperatura afeta a atividade de repasto sanguíneo das fêmeas do mosquito, no período de incubação extrínseca do vírus e em sua longevidade (Donalisio \& Freitas, 2015).

De acordo com o Ministério da Saúde em 2019, a taxa de incidência de casos de dengue no Brasil, era de 735,2 casos/100 mil habitantes, sendo notificados 1.544 .987 casos prováveis. Em ordem crescente tem-se a região Sul com 165,2 casos/100 mil habitantes, seguida da região Norte com 195,8 casos/100 mil habitantes, Nordeste com 376,7 casos/100 habitantes, Sudeste com 1.159,4 casos/100 mil habitantes, e Centro-Oeste com 1.349,1 casos/100 mil habitantes, sendo a região com mais casos de incidência já notificados para aquele ano. É ressaltado que nas regiões Sudeste e Centro-Oeste, mais especificamente nos estados de São Paulo, Minas Gerais e Goiás concentraram-se aproximadamente 68\% dos casos prováveis do Brasil. Na região Norte, teve-se uma elevação da incidência de dengue a partir da SE 44, principalmente nos estados de Roraima, Acre e Tocantins (Ministério da Saúde, 2020).

Já para o ano de 2020, foram notificados 971.136 casos prováveis de dengue até a SE 46, com taxa de incidência de 462,1 casos/100 mil habitantes no Brasil, sendo observado uma diminuição de casos e de incidência se comparados ao ano anterior de 2019. E acredita-se que isso se deve a diminuição das notificações no ano de 2020, no qual a região Norte teve incidência de 114,0 casos/100 mil habitantes, seguida da região Nordeste com 258,6 casos/100mil habitantes, Sudeste com 373,2/100 mil habitantes, Sul com 931,3 casos/100 mil habitantes e com maior incidência em ambos anos (2019 e 2020), ficou 
a região Centro-Oeste, com 1.187,4 casos/100 mil habitantes (Ministério da Saúde1, 2020).

De acordo com a distribuição dos prováveis casos de dengue no país durante a SE do início dos sintomas, exibe que, entre as SE 1 a 11, a curva de prevalência de possíveis casos no ano de 2020 superou o número de casos no mesmo período em 2019. Contudo, a partir da SE 12, há menos casos possíveis em comparação com 2019, Figura 1. Esta diminuição é capaz de ser associada à mobilização das equipes estaduais de vigilância epidemiológica em resposta ao surgimento da Pandemia de Coronavírus (COVID-19), que ocasionou subnotificação ou atrasos das arboviroses. Outra condição significativa que é capaz de estar relacionado cenário da pandemia é a preocupação das pessoas em procurar atendimento em instituições médicas (Ministério da Saúde1, 2020).

Figura 1 - Curva epidêmica dos casos prováveis de dengue, por SE de início de sintomas, Brasil, 2019 e 2020.*

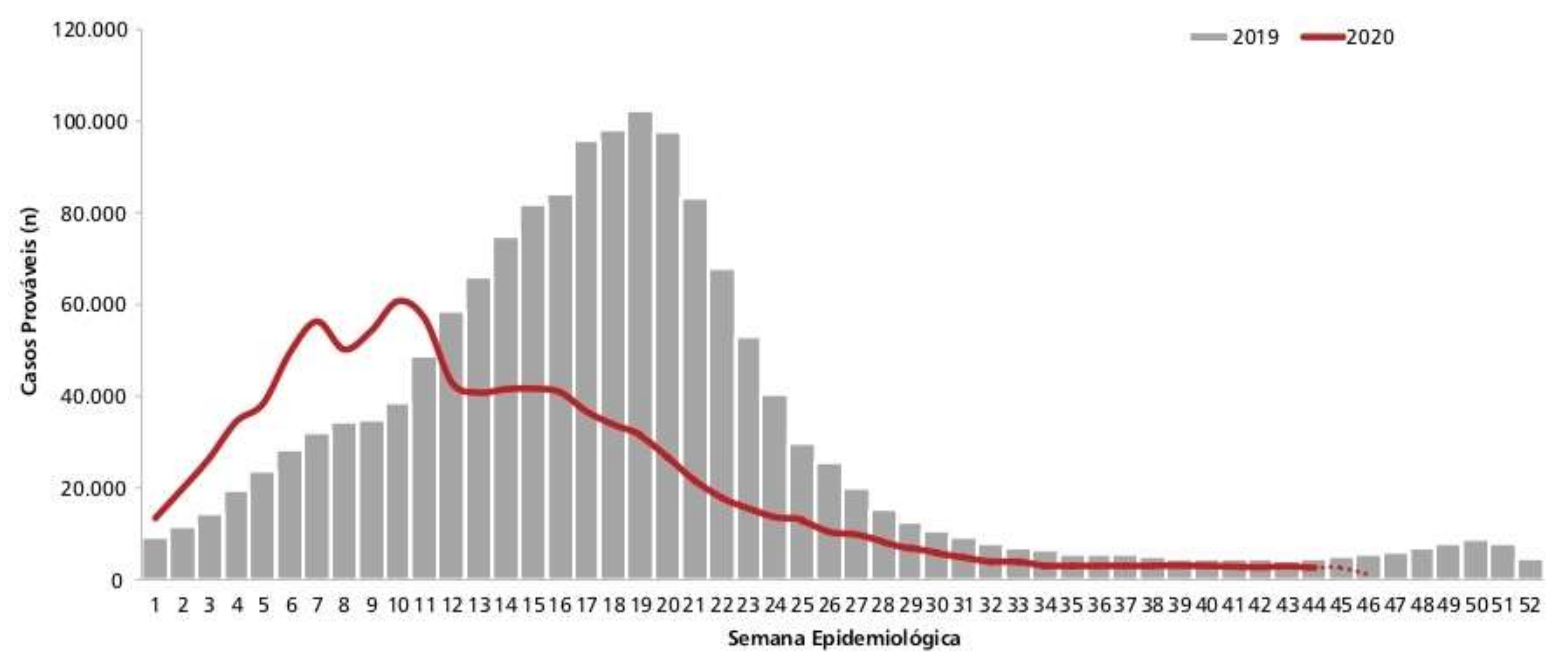

Nota: *Dados referentes a SE 46. Fonte: Sinan Online (banco de dados atualizado em 17/11/2020). Ministério da Saúde1, 2020, p. 2.

De acordo com o Ministério da Saúde1 (2020), entre os meses de janeiro a junho (SE 1 a SE 26), verificou-se 91,7\% dos casos de dengue, o que daria 890.362 casos prováveis com taxa de incidência de 423,7 casos/100 mil habitantes. Nesta circunstância, sobressaem os estados de Goiás, Distrito Federal, Mato Grosso do Sul, Paraná, Mato Grosso e Espírito Santo, conforme figura 2 (lado esquerdo). Já entre as SE 27 a SE 46, teve-se a notificação de 8,3\% dos casos prováveis no país, o que daria 80.774 casos prováveis, equivalente a 38,4 casos por 100 mil habitantes. Goiás e Distrito Federal, foram as unidades federais que exibiram a taxa de incidência acima de 100 casos/100 mil habitantes, conforme figura 2 (lado direito) (Ministério da Saúde1, 2020). 
Figura 2 - Distribuição da taxa de incidência de dengue por município, Brasil, SE 1 a 26 (esquerda) e SE 27 a 46 (direita) de 2020 .
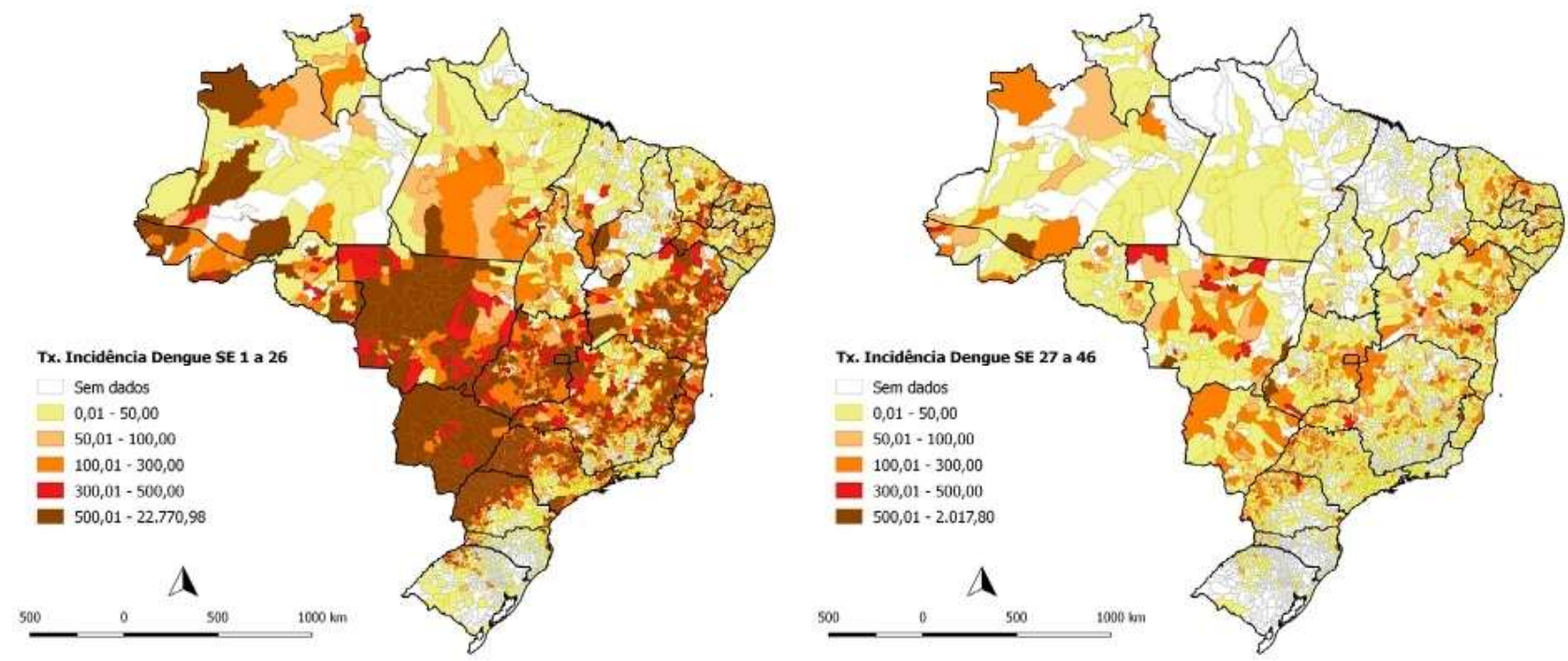

Fonte: Sinan Online (banco de dados atualizado em 17/11/2020). Ministério da Saúde1 (2020).

O Chikungunya (CHIKV) é um vírus de RNA pertencente à família Togaviridae, e do gênero Alphavirus. Foi descrito pela primeira vez na década de 50 na região em que hoje denomina-se a Tanzânia, no decorrer de um surto local conferido de início ao DEVN (Donalisio \& Freitas, 2015). Após a primeira descrição, dois modos diferentes de transmissão foram descritos: transmissão selvagem e suburbana na África (Aedes spp.) e transmissão urbana na Ásia (Aedes aegypti). Além disso, foi relatado que três genótipos diferentes se espalharam nas regiões do globo terrestre (África Central, África Ocidental - WA, Sul e Leste - ECSA e Ásia). Antes disso, quase não havia casos clínicos graves e nenhuma morte relacionada a esta infecção viral (Weaver, 2014).

Em 2019 para Chikungunya, obteve-se 132.205 casos prováveis notificados, com taxa de incidência de 62,9 casos/100 mil habitantes no Brasil. O Nordeste e o Sudeste, foram as regiões que demonstraram as mais elevadas taxas de incidência, sendo 59,4 casos/100 mil habitantes e 104,6 casos/100 mil habitantes, respectivamente. Rio Grande do Norte e Rio de Janeiro foram os estados que concentram 75,6\% dos casos prováveis (Ministério da Saúde, 2020).

Já para 2020, entre as SE 1 e 46, obteve-se 78.808 casos prováveis notificados de Chikungunya, com taxa de incidência de 37,5 casos/100 mil habitantes. Sendo observado que se teve uma diminuição nas SE notificadas, nos casos prováveis, bem como nas taxas de incidência. Mas mantendo as regiões com elevadas taxas de incidência (Sudeste e Nordeste) se comparado ao ano de 2019, porém o número de casos prováveis se inverteu, sendo que em 2019 o Sudeste teve 104,6, já em 2020 teve 22,7 casos/100 mil habitantes, sendo observado uma queda na taxa de incidência. Bem como o Nordeste que em 2019, obteve taxa de incidência de 59,4 casos, já em 2020 teve 99,4 casos/100 mil habitantes, sendo verificado um aumento de 40 casos de 2019 para 2020, conforme Figura 3 (Ministério da Saúde1, 2020). 
Figura 3 - Curva epidêmica dos casos prováveis de chikungunya, por semanas epidemiológicas de início de sintomas, Brasil, 2019 e $2020 *$

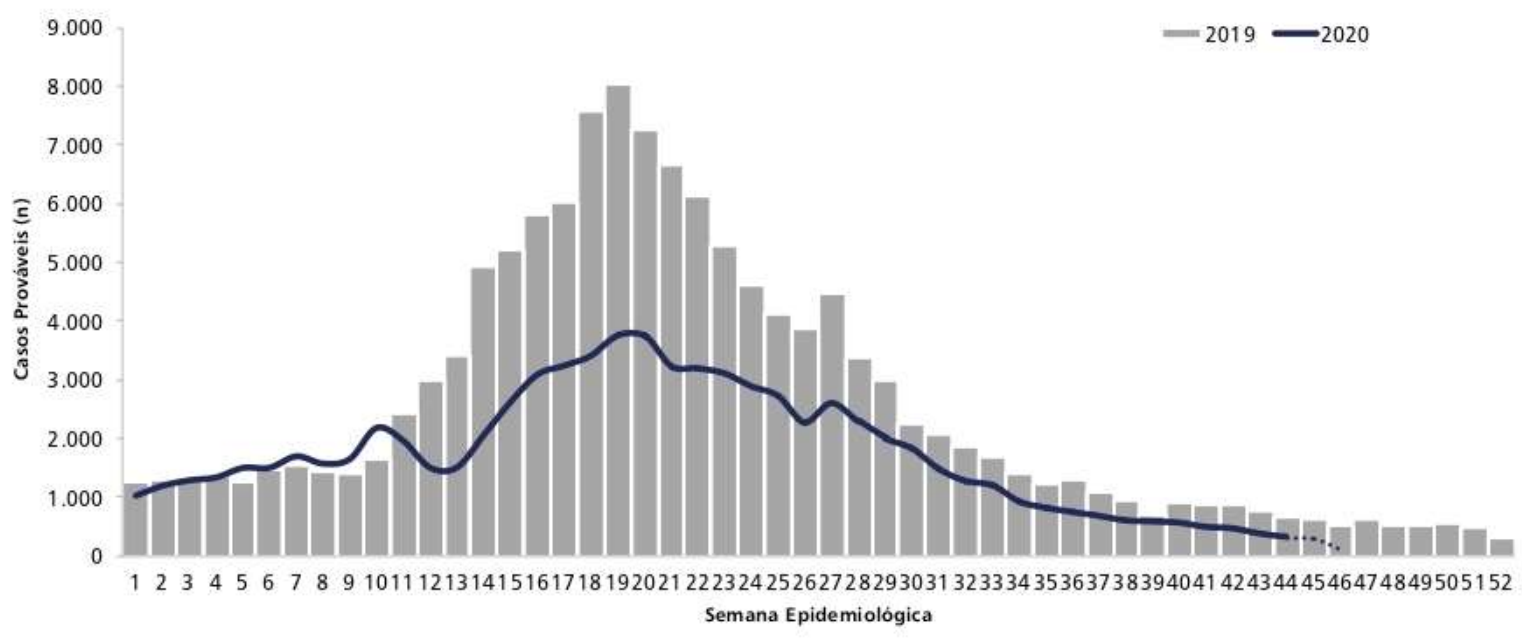

Nota: *Dados referentes a SE 46. Fonte: Sinan Online (banco de dados atualizado em 17/11/2020). Ministério da Saúde1 (2020) 3.

De acordo com a Figura 4 (lado esquerdo), até a SE 26, obteve-se 59.215 casos prováveis notificados para Chikungunya (75,1\%), com taxa de incidência de 28,2 casos/100 mil habitantes, tendo destaque os estados do Rio Grande do Norte, Bahia e Espírito Santo. Ainda na figura 4, mas do lado direito é representado pelas SE 27 a 46, nas quais se obteve 19.593 casos prováveis notificados para Chikungunya (24,9\%), com taxa de incidência de 9,3 casos/100 mil habitantes. Neste período, o estado do Sergipe exibiu uma taxa de incidência acima de 100 casos/100 mil habitantes, o restante dos estados obteve uma taxa de incidência menor ou igual a 100 casos (Ministério da Saúde1, 2020).

Figura 4 - Distribuição da taxa de incidência de chikungunya por município, Brasil, SE 1 a 26 (esquerda) e SE 27 a 46 (direita) de 2020.
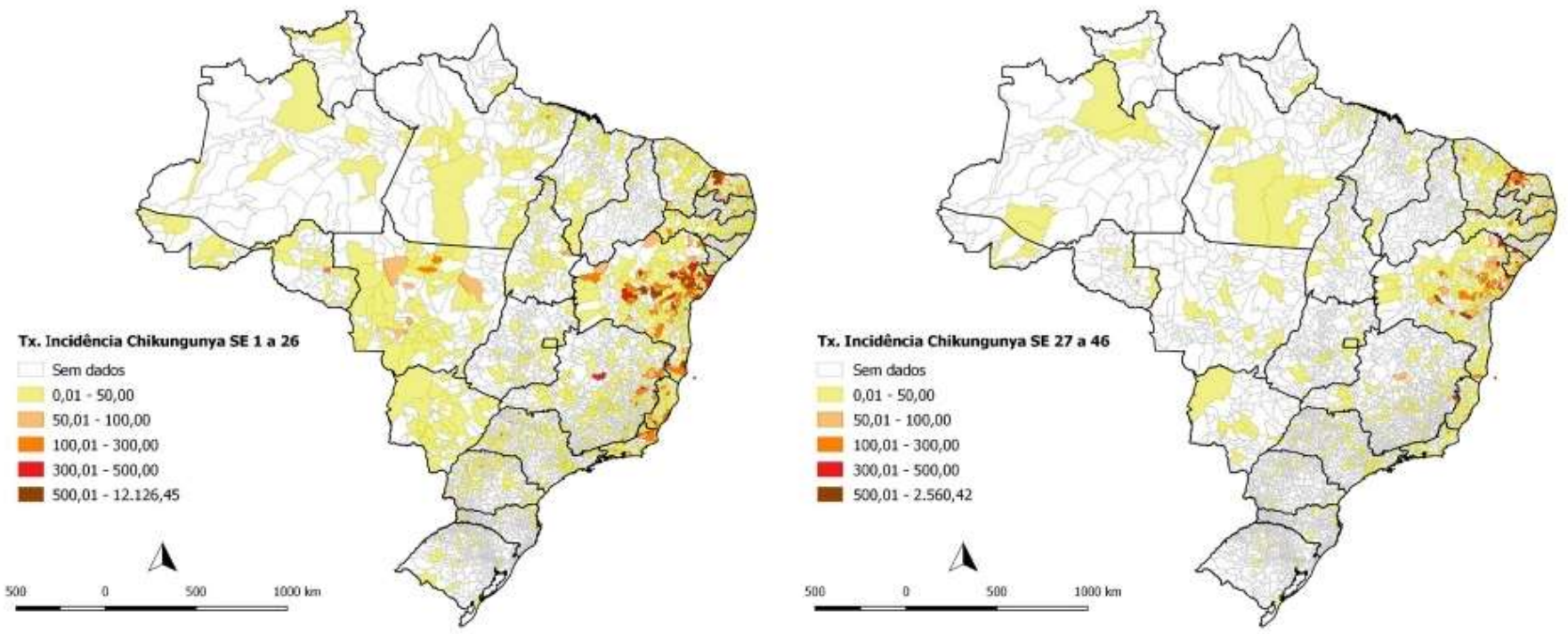

Fonte: Sinan Online (banco de dados atualizado em 17/11/2020). Ministério da Saúde1 (2020).

Foram notificados 1.419 casos de dengue grave em 2019, como também 18.740 casos de dengue com sinais de alarme. Neste mesmo ano, foram notificados 782 óbitos por dengue no Brasil, tendo as maiores taxas de letalidade as regiões Sul com 0,06\% e Centro-Oeste com 0,08\% levando em consideração os casos prováveis de dengue. Para Chikungunya, foram 
notificados 92 óbitos, tendo as maiores taxas de letalidade as regiões Nordeste e Sudeste com 0,07\% e Centro-Oeste com 0,09\%, apesar de 66 óbitos (71,7\%) serem pertencentes ao estado do Rio de Janeiro. De acordo com a Figura 5, idosos a partir de 60 anos tiveram a taxa de letalidade maior para dengue e chikungunya, ainda nesta mesma categoria, idosos acima de 80 anos foram os mais afetados, e ressalta-se que para a faixa etária, menores de 1 ano, teve-se um destaque para a chikungunya. $\mathrm{Na}$ análise de risco relativo de morrer por dengue, tem-se a faixa etária de 80 anos ou mais com 129,7 vezes mais chance que a de 1 a 4 anos. Ao mesmo tempo que, para a chikungunya, a faixa etária de 80 anos ou mais tem 87,4 vezes mais chance que a de 10 a 19, ao mesmo passo que menores de 1 ano tem 31 vezes mais (Ministério da Saúde, 2020).

Figura 5 - Taxa de letalidade de dengue e chikungunya, por faixa etária no Brasil, 2019.

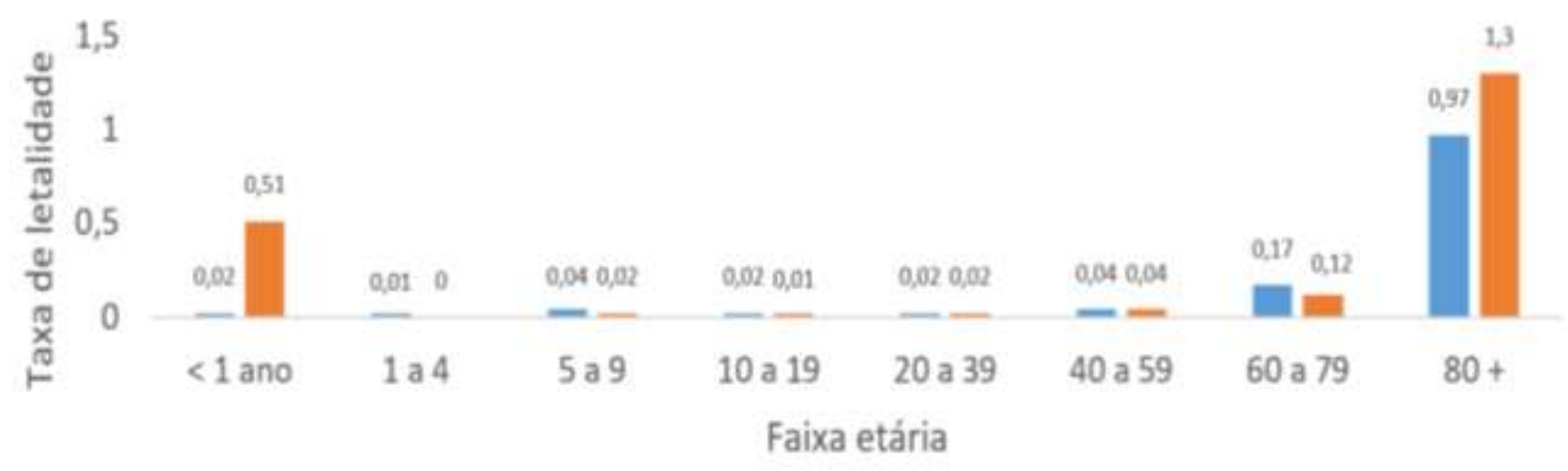

Dengue $=$ Chikungunya

Fonte: adaptado de Sinan Online (banco de dados de 2019 atualizado em 30/12/2019), Ministério da Saúde (2020).

O ZIKV foi isolado pela primeira vez em macacos Rhesus na África em 1947, e mais precisamente em Uganda. Hoje, é responsável por arbovírus emergentes no mundo. Até recentemente, apenas casos humanos esporádicos foram relatados. Em 2007, casos relacionados ao ZIKV foram registrados fora da Ásia e do continente africano, com foco na epidemia na Polinésia Francesa e na disseminação do vírus em vários países da Oceania (Faye, et al., 2008).

O vírus Zika (ZIKV) é um vírus de RNA pertencente à família Flaviviridae, e ao gênero Flavivirus, sendo seu genoma constituído de uma molécula de RNA de cadeia simples. Alguns estudos relataram três cepas principais de ZIKV, uma primitiva da Ásia e as outras duas da África. A transmissão do ZIKV é feita principalmente pelas espécies de mosquitos Aedes aegypti e Aedes albopictus. É relatado a possibilidade da transmissão viral por relações sexuais, transfusão de sangue e transmissão vertical (Luz, et al., 2015).

Em 2019, entre as SE 1 a 48, teve-se a notificação de 10.768 casos prováveis de Zika no Brasil, com taxa de incidência de 5,1 casos/100 mil habitantes. Entre as regiões que tiveram maiores taxas de incidência, em ordem crescente foram as regiões Sul com 0,4 casos/100 mil habitantes, seguida da Sudeste com 4,0 casos/100 mil habitantes, Norte com 4,3 casos/100 mil habitantes, Centro-Oeste com 5,8 casos/100 mil habitantes e com a maior taxa de incidência, a região Nordeste, com 9,5 casos/100 mil habitantes (Ministério da Saúde, 2020).

Já em 2020, entre as SE 1 a 43, tiveram 7.006 casos prováveis notificados no Brasil, com taxa de incidência de 3,3 casos/100 mil habitantes, demonstrando diminuição tanto no período de notificação, quanto na taxa de incidência. Se comparado ao ano de 2019, a região Nordeste ainda continuou com a maior taxa de incidência, com 9,0 casos/100 mil habitantes, seguida da região Centro-Oeste com 3,6 casos/100 mil habitantes e Norte com 2,0 casos/100 mil habitantes, as demais regiões não foram descritas no boletim epidemiológico, conforme figura 6 . E a Bahia concentrou $49,2 \%$ dos casos 
notificados de Zika do país (Ministério da Saúde1, 2020).

Figura 6 - Curva epidêmica dos casos prováveis de zika, por semanas epidemiológicas de início de sintomas, Brasil, 2019 e 2020.*

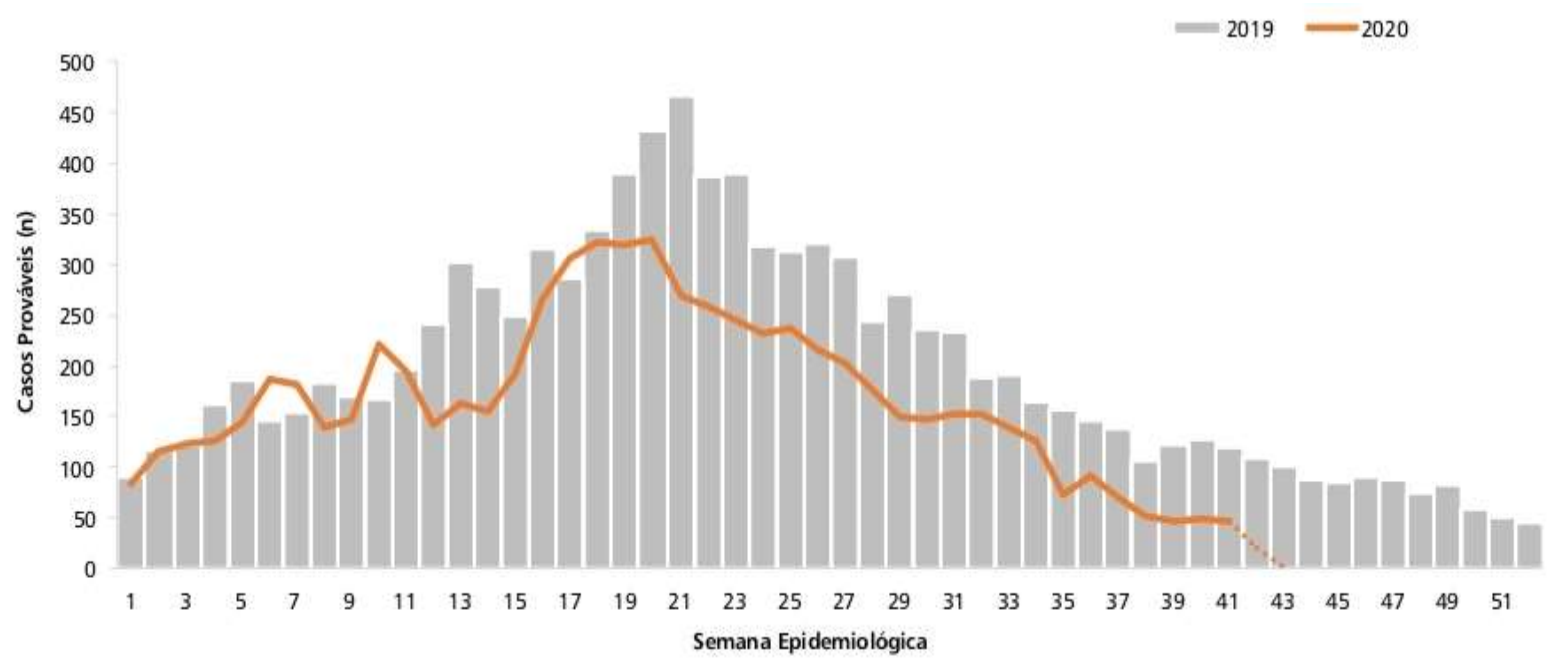

Nota: *Dados referentes a SE 43. Fonte: Sinan Net (banco de dados atualizado em 28/10/2020). Ministério da Saúde1 (2020).

A partir da SE 27 foi observado uma tendência de redução de casos de zika, bem como para dengue e chikungunya. No estado da Bahia, foram notificados casos de zika no decorrer de todas as SE, sendo a SE 1 a 26 com 2.909 casos prováveis (54,7\%) e a SE 27 a 43 com menos casos notificados, com 537 casos prováveis (31,6\%). Em relação as mulheres grávidas, foram notificados 595 casos prováveis e destes 201 foram confirmados no Brasil (Ministério da Saúde1, 2020).

De acordo com a Figura 7 (lado esquerdo), foram notificados 5.309 casos prováveis de zika entre as SE 1 a 26 (75,8\% dos casos prováveis), sendo incidente em 2,5 casos/100 mil habitantes e tendo como destaque os estados do Rio Grande do Norte, Bahia e Mato Grosso. Ainda na Figura 7 (lado direito), entre as SE 27 a 43, foram notificados 1.697 casos prováveis de zika (24,3\%), com taxa de incidência de 0,8 casos/100 mil habitantes, demonstrando uma queda nos casos notificados e na taxa de incidência se comparado ao período anterior SE 1 a 26 (Ministério da Saúde1, 2020). 
Figura 7 - Distribuição da taxa de incidência de zika por município, Brasil, SE 1 a 26 (esquerda) e SE 27 a 43 (direita) de 2020 .
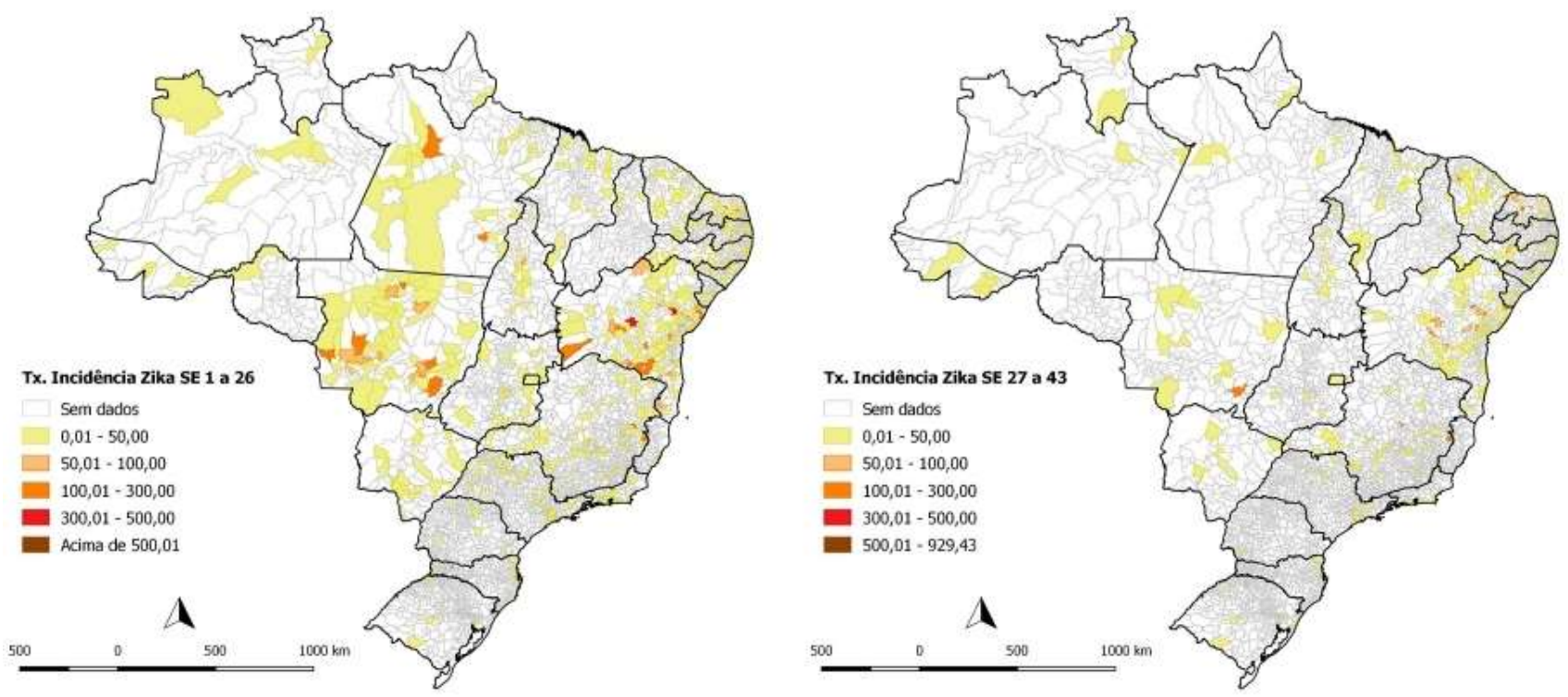

Fonte: Sinan Online (banco de dados atualizado em 28/10/2020). Ministério da Saúde1 (2020).

Por razões de similaridades, o manejo clínico é comprometido no Brasil, uma vez que se tem a cocirculação de infecções por dengue, chikungunya e zika, sendo pouco relatado o impacto de uma cocirculação desses vírus. Um exemplo é a reinfecção pelos variados sorotipos de dengue (DENV), e uma interação entre as arboviroses dengue (DENV sorotipos 1-4), chikungunya e zika poderiam hipoteticamente manifestarem-se em viremias mais acentuadas ou diferentes alterações no sistema imunológico que, por sua vez, atuariam como um gatilho para doenças autoimunes, sendo a síndrome de Guillainbarré, um exemplo dessas doenças (Duffy, et al., 2009; Ioos, et al., 2014; Roth, et al., 2014).

Queiroz, et al., (2020) reportam que as elevadas taxas de incidência de arboviroses propagadas pelos insetos do gênero Aedes nos últimos anos no Brasil são capazes de estarem relacionadas a carência no fornecimento de água potável. E tal carência pode ser associada as secas intensas, inadequação da gestão na prestação de serviços ou pela ausência de políticas públicas, e supostamente pela união destes fatores. Contudo, são capazes de estarem relacionadas também à não adequação do acesso aos outros elementos inclusos no saneamento, tais como, drenagem de águas pluviais, esgotamento sanitário e gestão apropriada dos resíduos sólidos.

Lima-Camara (2016) ressalta que mesmo com as intervenções e alterações dos ecossistemas pelas mãos humanas, vários fatores estão associados ao aparecimento de arboviroses no país. Como por exemplo, o aumento populacional e de forma desordenada, os seguimentos de globalização e ampliação do intercâmbio internacional, como também as variações climáticas. Enfatizando o aumento populacional e de forma desordenada, Aagaard-Hansen, et al., (2010) reportam que o deslocamento de forma voluntária (lazer, trabalho ou estudo) ou involuntária (refugiado, devido a um desastre natural ou ambiental) eleva o risco de o homem transportar e disseminar microrganismos patogênicos que ainda não possuem identificação para outras áreas. Com isso, tendo novos sorotipos ou cepas multirresistentes a um determinado vírus já identificado, gerando ali a aparição ou reemergência de uma doença. Um exemplo de disseminação, foi a pandemia de doença do coronavírus (COVID-19) ocasionada pelo vírus SARS-CoV-2, que se estendeu rapidamente por todo o mundo em um curto período de tempo (Baloch, et al., 2020).

Ainda Lima-Camara (2016), diz que outro fator essencial na dinâmica de propagação de microrganismos ao ser humano se dá pelo aquecimento global. Uma vez que, a elevação da temperatura impacta nos mosquitos vetores, diminuindo o 
tempo de crescimento larval e, com isso, elevando de forma rápida a população de mosquitos adultos, como também amplifica a disseminação de doenças envolvendo vetores. Em consequência, minimiza o período de incubação extrínseca, isto é, o tempo em que o vírus leva para ir até a glândula salivar do mosquito, deixando-o apto para a propagação do causador da patologia. Países com climas tropicais exibem condições satisfatórias (climática e ambiental) para a propagação de novas infecções, porém em países com clima temperado a circulação de alguns arbovírus também foi notificada.

Outro obstáculo para o controle vetorial é o próprio meio ambiente, pois com o crescimento urbano de forma desordenada, muitos rios e valas acabam sofrendo a interferência humana e sendo poluídos, como também os vetores ganham locais artificiais de oviposição para desenvolvimento e crescimento dos mosquitos, em particular o Aedes aegypti e o Culex quinquefasciatus. As alterações no clima também exercem contribuições na propagação dos mosquitos vetores. Chuvas frequentes em certos locais, como o quintal, garagem a céu aberto possuindo pneus e/ou outros equipamentos que podem reter água das chuvas, são fortes candidatos a criadouros artificiais para as fêmeas do mosquito depositarem seus ovos. Mas também em períodos de estiagem, em muitos estados têm-se a estocagem de água em galões e barris, servindo também como criadouros artificiais e consequente disseminação e elevação da população de mosquitos adultos (Meason \& Paterson, 2014; Lima-Camara, 2016).

Contudo, Sommerfeld e Kroeger (2012) demonstraram que unicamente, as variáveis sanitárias não elucidam a heterogeneidade das patologias, uma vez que são multifatoriais, portanto, são peças chave para retratar o acontecimento das infecções por arbovírus. Cleton, et al. (2012), descrevem que as manifestações clínicas das infecções ocasionadas por arbovírus no homem é capaz de se manifestar de formas diferentes, como por exemplo uma doença febril indistinta, moderada ou grave, artralgia, síndromes hemorrágica e/ou neurológica, como também aparecimento de erupções cutâneas.

\section{Considerações Finais}

Portanto, fica claro que as arboviroses ocasionam um grande impacto na saúde pública que vão desde a identificação do agente causador até as medidas de controle dos vetores. Com isso, é ressaltado a importância de saneamento como método de controle da incidência e prevalência das infecções por arbovírus. Como também, a detecção de doenças emergentes e reemergentes nos municípios, baseando-se nos reforços e valorização da vigilância epidemiológica, sendo necessária uma rede de laboratórios com capacidade de atender estes locais, com instrumentação adequada, profissionais capacitados e insumos necessários para a realização dos testes.

Outro ponto interessante para se ter o controle satisfatório das arboviroses, seriam atividades do campo da saúde ambiental, vigilância sanitária, saúde pública veterinária e consequente maior acesso ao saneamento básico para muitas regiões carentes, visto que este é um fator primordial para a propagação de múltiplas doenças.

E por fim, ter uma ligação com universidades e institutos de pesquisas, uma vez que eles são fundamentais para o conhecimento e identificação destas doenças e seus vetores. Com isso se faz necessária pesquisas relacionadas ao entendimento dos ciclos de transmissibilidade urbana e ofertar uma intervenção de forma estratégica para contribuir no seu controle e impedir a urbanização vetorial futura.

\section{Referências}

Aagaard-Hansen, J., Nombela, N., \& Alvar, J. (2010). Population movement: a key factor in the epidemiology of neglected tropical diseases. Trop Med Int Health. 15 (11): 1281-8. 10.1111/ j.1365-3156.2010.02629.x

Alen, M. M. F., \& Schols, D. (2012). Dengue virus entry as target for antiviral therapy. J Trop Med. (ID 628475):1-13. 10.1155/2012/628475.

Baloch, S., Baloch, M. A., Zheng, T., \& Pei, X. (2020). The Coronavirus Disease 2019 (COVID-19) Pandemic. Tohoku J Exp Med. Apr; 250(4):271-278. 10.1620/tjem.250.271. 
Cleton, N., Koopmans, M., Reimerink, J., Godeke, G. J., \& Reusken, C. (2012). Come fly with me: review of clinically important arboviruses for global travelers. J Clin Virol. Nov; 55(3):191-203. 10.1016/j.jcv.2012.07.004

Donalisio, M. R., Freitas, A. R. R., \& Zuben, A. P. B. (2017). VonArboviruses emerging in Brazil: challenges for clinic and implications for public health. Revista de Saúde Pública [online]. v. 51, 30. https://doi.org/10.1590/S1518-8787.2017051006889.

Duffy, M. R., Chen, T. H., Hancock, W. T., Powers, A. M., Kool, J. L., Lanciotti, R. S., et al. (2009). Zika virus outbreak on Yap Island, Federated States of Micronesia. N Engl J Med, 360(24):2536-43. https://doi.org/10.1056/NEJMoa0805715

Fauci, A. S., \& Morens, D. M. (2012). The perpetual challenge of infectious diseases. N Engl J Med. 366(5):454-61. 10.1056/NEJMra1108296

Faye, O., Faye, O., Dupressoir, A., Weidmann, M., Ndiaye, M., Alpha Sall, A. (2008). One-step RT-PCR for detection of Zika virus. J Clin Virology. 43(1):96-101. 10.1016/j.jcv.2008.05.005. 18674965.

Gil, A. C. (2002). Como elaborar projetos de pesquisa. (4a ed.), Atlas (2002).

Godoy, A. S. (1995). Introdução à pesquisa qualitativa e suas possibilidades. Revista de Administração de Empresas, 35(2), 57-63.

Instituto Brasileiro de Geografia e Estatística (IBGE). (2020). Países mais extensos do mundo. https://cnae.ibge.gov.br/en/component/content/article/947a12/7a12-vamos-conhecer-o-brasil/nosso-territorio/1461-o-brasil-no-mundo.html

Ioos, S., Mallet, H. P., Leparc Goffart, I., Gauthier, V., Cardoso, T., \& Herida, M. (2014). Current Zika virus epidemiology and recent epidemics. Med Mal Infect, 44(7):302-7. https://doi.org/10.1016/j.medmal.2014.04.008.

Lima-Camara, T. N. (2016). Emerging arboviruses and public health challenges in Brazil. Revista de Saúde Pública, 50, 36. https://doi.org/10.1590/S15188787.2016050006791

Lopes N., Nozawa C., \& Linhares R. E. C. (2014). Características gerais e epidemiologia dos arbovírus emergentes no Brasil. Revista Pan-Amazônica de Saúde, 5:55-64. 10.5123/S2176-62232014000300007

Luz, K. G., Santos, G. I. V., \& Vieira, R. M. (2015). Febre pelo vírus Zika. Epidemiologia e Serviços de Saúde, 24, 785-788. http://dx.doi.org/10.5123/S167949742015000400021

Meason, B., \& Paterson, R. (2014). Chikungunya, mudança climática e direitos humanos. Direitos de saúde hum. 16 (1): 105-12.

Ministério da saúde. (2020). Monitoramento dos casos de arboviroses urbanas transmitidas pelo Aedes (dengue, chikungunya e Zika), Semanas Epidemiológicas 01 a 52. Boletim Epidemiológico, 51 (02), 1-5. Recuperado 5 jan. 2021, de: https://antigo.saude.gov.br/images/pdf/2020/janeiro/20/Boletimepidemiologico-SVS-02-1-.pdf

Ministério da saúde1. (2020). Monitoramento dos casos de arboviroses urbanas transmitidas pelo Aedes Aegypti (dengue, chikungunya e zika), semanas epidemiológicas 1 a 46. Boletim Epidemiológico, $51 \quad$ (48), 1-7. https://www.gov.br/saude/pt-br/media/pdf/2020/dezembro/11/bolet im_epidemiologico_svs_48.pdf

Ministério do Meio Ambiente (MMA). (2020). Biodiversidade Brasileira. https://antigo.mma.gov.br/biodiversidade/biodiversidade-brasileira.html

Paz, F. A. Z., \& Bercini, M. A. (2009). Doenças Emergentes e Reemergentes no Contexto da Saúde Pública. http://www.boletimdasaude.rs.gov.br/conteu do/1441/doen\%C3\%A7as-emergentes-e-reemergentes-no-contexto-da-sa\%C3\%BAde-p\%C3\%BAblica-

Pereira, A. S., Shitsuka, D. M., Parreira, F. J., Shitsuka, R. (2018). Metodologia da pesquisa científica. UFSM. https://repositorio.ufsm.br/bitstream/handle/1/ 15824/Lic_Computacao_Metodologia-Pesquisa-Cientifica.pdf?sequence=1

Queiroz, J. T. M., Silva, P. N., Heller, L. (2020). Novos pressupostos para o saneamento no controle de arboviroses no Brasil. Cadernos de Saúde Pública, 36(5), e00223719. https://doi.org/10.1590/0102-311x00223719

Roth, A., Mercier, A., Lepers, C., Hoy, D., Duituturaga, S., Benyon, E., et al. (2014). Concurrent outbreaks of dengue, chikungunya and Zika virus infections: an unprecedented epidemic wave of mosquito-borne viruses in the Pacific 2012-2014. Euro Surveill. 19(41)10.2807/1560-7917.es2014.19.41.20929

Rust, R. S. (2012). Human arboviral encephalitis. Semin Pediatr Neurol. 19(3):130-51. 10.1016/j.spen.2012.03.002

Samuel, G. H., Adelman, Z. N., Myles, K. M. (2016). Temperature-dependent effects on the replication and transmission of arthropod-borne viruses in their insect hosts. Curr Opin Insect Sci. 16:108-113. 10.1016/j.cois.2016.06.005

Sommerfeld, J., \& Kroege, A. (2012). Eco-bio-social research on dengue in Asia: a multicountry study on ecosystem and community-based approaches for the control of dengue vectors in urban and peri-urban Asia. Pathog Glob Health. 106(8):428-35. https://doi.org/106:428-35.10.1179/ 2047773212Y.0000000055

Triviños, A. N. S. (1987). Introdução à pesquisa em ciências sociais: a pesquisa qualitativa em educação. Atlas, 100.

Weaver, S. C. (2014). Arrival of chikungunya virus in the new world: prospects for spread and impact on public health. PLoS neglected tropical diseases, 8(6), e2921. 10.1371/journal.pntd.0002921.

Weaver, S. C., \& Reisen, W. K. (2010). Present and future arboviral threats. Antiviral Research, 85 (2), 328-345. 10.1016/ j.antiviral.2009.10.008 